Ethiopian Journal of Environmental Studies \& Management 7 Suppl.: 780 - 789, 2014.

ISSN:1998-0507

doi: http://dx.doi.org/10.4314/ejesm.v7i1.8S

Submitted: August 31, 2014

Accepted: November 08, 2014

\title{
RISING TO THE CHALLENGE: WHAT SORT OF CAPACITY DOES GHANA NEED TO ADAPT TO CLIMATE CHANGE?
}

\author{
*MUSAH-SURUGU, J.I. AND AHENKAN, A. \\ Department of Public Administration and Health Services Management, University of Ghana \\ Business School, P. O. Box LG 78, Legon, Accra
}

\begin{abstract}
In both development policy and practice climate change adaptation and adaptive capacity have become the central theme in global climate change discourse. This is because climate change adaptation is not just a development issue but also survival hitch threatening most developing economies. This paper attempts to examine the capacity Ghana need to effectively adapt to climate change. The paper is extensively theoretical with minimal interview data collected from the Ghanaian business community, climate change graduate students, multi-disciplinary researchers and policy practitioners in the field of climate change. It was found that capacity needed to address climate change in Ghana is not different from those needed to address any social hazards, though it requires capacity beyond business as usual. The required capacities include timely information dissemination, training and research, technological penetration, leadership, financial resource, institutional resourcing and collaboration. Recommendations were made for improvement in each of these needed capacities.
\end{abstract}

Key Words: Adaptation, Adaptive capacity, Climate change, Environmental stress

\section{Introduction}

Climate change is an urgent and complex problem to every living creature across the world, most especially in developing country like Ghana. It is clearly evident that the increasing incidents of floods, drying water resources, loss of forest belt, reduction in yields, and increasing incident of temperature related diseases in several parts of Ghana with devastating effect on life and property are clear manifestations of climate change. Climate change is one of the most serious environmental and socio-economic threats the world has ever faced (Boon and Ahenkan, 2011). Across the globe climatologist and climate change commentators have often stressed that climate change is real and happening faster than human society have previously assumed with serious devastating impacts in developing countries, particularly on the Africa continent (OECD, 2008). The devastation of climate related impacts has undercut livelihoods, endangered natural ecosystems, and challenged the capacity of institutions (Lemos et al., 2007). Historical evidence have shown that the impact of climate change and other environmental stressors have led to collapsed of established dynasties (Butzer, 2011), political hostilities (Butzer, 2011.), famine, hunger and malnutrition (Butzer and Endfield (2012), epidemics (McMichael and Lindgren (2011), migration to new areas (McMichael and Lindgren (2011), forced people to change the crops types for cultivation and modified their shelter (Butzer, 2011). 
The impact of climate change is more immense and threatening in Africa where capacity to adapt is very low (Jones, 2010; OECD, 2008). Therefore in Africa Adaptation is a survival priority and not a choice. Having the right capacity mix is an important resource to build societal resilience against the impacts of climate change.

Adaptation is largely conceptualize to mean an adjustment in natural or human systems to build the resilience of an organism or institutions to cope with the effects of climate change (Wilbanks and Kates 2010; UNDP, 2005; and IPCC, 2001). Adaptive capacity on the other hand is closely associated with the concept of adaptability, robustness and stability of a system to cope with the effect of climate change. The IPCC (2007) defines adaptive capacity as the ability of a system to adjust to climate change to moderate potential damages, to take advantage of opportunities, or to cope with the consequences. A system has high adaptive capacity if it is able to react swiftly and flexibly to the effects of climate change.

Climatic change in the $21^{\text {st }}$ century calls for a more realistic and prudent human and ecosystem capacity development for a coherent management. According to MEST (2010) though Ghana's contribution to the causative factors of global climate change has been negligible, its impact on the Ghanaian economy is substantial. Unfortunately, capacity to tackle and manage it effectively is almost nonexistent (MEST, 2010). Meanwhile one's ability to respond well to climate change to a large extent depends on stakeholder's capacity (Jones, 2010; Kuriakose et al., 2009 and Lemos et al., 2007). Climate change adaptive capacity built on sophisticated and well informed socio-political, economic, and technological choices is necessary to integrate climate change management into sustainable development path.
Ghana depends so much on sectors that are sensitive to climate change: thus, agriculture, forestry and energy production etc. invariably Ghana is very vulnerable to climate change and variability as already noted by the MEST (2010). The situation indicates that Ghana's effort to sustain it growth and become a fully-fledged middle income country by 2020 could be interrupted by it weak adaptive capacity status. Evidence already shows the impact of climate change on Ghana's national economy, with clear signs that the coastal zone, agriculture and water resources, infrastructure, energy and human shelter are all affected, as well as poverty, health and livelihoods. This study therefore examines the capacity Ghana need to effectively adapt to the changing climate by asking the following questions:

What sort of capacity does Ghana need to adapt to climate change?

Why are those capacities necessary?

What are the challenges to developing such capacity?

This study provides synthesized information on climate change adaptive capacity that Ghana need in other to cope with current and future changes in climate. This information could be used to support the incorporation of climate change management into national development agenda. For example in Ghana, attention on climate change is gaining momentum both at the highest political level and across sectors and therefore climate change is being mainstreamed into national development framework, particularly in the just ended Ghana's Shared Growth and Development Agenda (GSGDA-2010-2013). Additionally, Climate change is among various thematic areas receiving support under the "Natural Resources and Environment Governance" initiative (NREG) among key development partners and the World Bank. Therefore providing this synthesized information on 
capacity needs is timely and relevant to both practitioners and academia.

\section{Study Methodology}

The study is entirely qualitative based on in-depth interviews. A total of 30 interviews were conducted during the period between March, 2013 and June, 2014. The B4CProject (Building Capacity to meet Climate Change Challenges) been implemented by the Center for African Wetlands and the Building Stronger Universities (BSU) Climate Change and Environment components were the main route through which this data was collected. The list of the interviewees includes lecturer from Arhus University, University of Ghana, Post graduate students of climate change and other analogue sciences, participants of short $\mathrm{PhD}$ program on climate change adaptation, policy makers in fore front of climate change issues in Ghana. All the interviews were conducted face-to-face and in accordance with the British Psychological Society (BPS) ethical principles for conducting research on human participants. This means that all interviewees were offered the opportunity to participate anonymously. They were also given the choice of whether they wanted to represent themselves (as an individual) or their organization (where appropriate). With the prior consent of the participant, each interview was recorded and subsequently transcribed. The interviews typically lasted between 30-60 minutes, and the interviewer used a set of 15 questions as prompts that covered a range of aspects of climate change capacity issues identified in the literature and the challenges to improving adaptive capacity in developing country. The qualitative data was transcribed and analysed thematically based on the objective of the study.

\section{Results and Discussion}

Types of capacity Ghana needs to effectively adapt to climate change.
Does Ghana need institutional and strategic policy capacity to respond to ongoing impact or expected impact of climate change?

In the focus group discussion some respondents clearly indicated that the frequent flooding in Accra is an indication of ongoing impact of climate change. They therefore explained that both formal and informal rules needed enforcement to ensure strict implementation of existing urban building standards, and prevent building on drains and "traditional water "channels. Institutions are the 'rules' that govern belief systems, behavior and organizational structure (Ostrom, 2005). Communities with well-developed social institutions are typically better able to respond to a changing environment than those with less effective institutional arrangements. Since adaptive capacity are classified/segregated along the lines of age, ethnicity, class, religion and gender' (Adger et al., 2007), institutions that allow for equitable opportunities to access resources are likely to promote adaptive capacity within a community.

Also they indicated that strategic policy will allocate responsibility, resource and methods of accountability. Respondent mentioned the UNFCCC, Kyoto protocol, Montreal protocol and the Nairobi work program on impacts, vulnerability and adaptation to climate change as example of policy initiative within the international domain to help adapt and mitigate greenhouse gases. These policy directions provide the needed capacity to the global community to manage climate change impact. Therefore Ghana needs similar policy document that will serve as a blue print for managing climate change impact. According to Smithers et al. (2008) policy framework on climate change is an agency capacity requirement that is necessary to evaluate a country's responds to climate change impact. They noted that policy provides adaptation principles necessary for taking stock of what 
is known and not known, develop knowledge and plan strategically.

Does Ghana need extra technological penetration beyond business as usual to respond to ongoing impact or expected impact of climate change?

Countries with strong technology penetration appear to have the highest tendency of cope with the impacts of climate change. In a decade on intense impacts of climate, communities need to modify existing practices, resources and patterns of behaviors in other to adopt. Key ability to alter existing practices, resources and patterns of behaviors is technological penetration or innovation and adoption. Respondents indicated that energy deficit has become pronounced partly due to frequent reduction in water volume of Akosmbo Dam which is the main hydro power source for Ghana. Respondents therefore indicated that Ghana needs technological innovation and adoption which could utilize its abundant wind resources, solar resources and potential rivers that could be converted into dams to generate extra power for both domestic and industrial consumption.

Robert (2010) noted that technological advancement is a key strategy towards addressing climate change. The National Academies report (2010) on limiting the magnitude of future climate change concluded that ". . . renewable energy technologies that do not emit GHGs, that are resistant to changing climate and provide long term energy security are an important and viable part of a near-term strategy for mitigation and adaptation". Respondents noted that "diffusion of climate friendly and user friendly technology is important to improve Ghana's capacity to adapting to climate change". Technological diffusion can either be local or foreign. Local technology for irrigation, flood management, and building storm resistant infrastructure is very important just like any other climate friendly western technology.

From the panel discussion some respondent confirmed that technological penetration could improve communication networks, data exchange, innovation in existing practices, provide early warning systems, measure system coping range and vulnerability and also provide accurate intervention require..

Does Ghana need to train people to help develop, implement, evaluate and further advice on current and future responds to the impact of climate change?

Information on climate data, such as temperature, rainfall and the frequency of extreme events, and non-climatic data, such as sectors resilience, exposure, sensitivity and vulnerability is very important for adaptation planning. The ability or capacity to access this information relies heavily on the level of expertise a country has. Presently, respondents acknowledged that Ghana has expertise deficit in areas such as climate science professionals, environmental media practitioners who can appreciates climate science and present it in a consumable form to it audience, institutional capacities (under resourced Ghana meteorological agency), center of excellence on climate change etc. Ghana needs to train people in climate change science and policy. This training will equip institutions and individuals and will eventually stimulate research into the diverse areas of climate change impact.

Does Ghana need dynamic shift in Leadership commitment (political capital) to respond to ongoing impact or expected impact of climate change?

Respondents clearly indicated that climate change calls for good governance. They explained that political leadership preparedness and willingness to mainstream climate change in their decision making and development agenda is very critical, in every bit of adaptation. For example the setup of 
institutions within countries is largely the responsibility of national governments, possibly supported initiatives of the UNFCCC, bilateral and multilateral support programmes.

One respondent had this to say:

..when extreme weather events like heavy down poor in Ghana interrupts technical infrastructure, buildings and further disrupt municipal activities and people health, it does not only explain human system exposure or sensitivity to the hazards, but also failures of previous political decisions and administrative permissions that might have worsen vulnerability. An effective leadership is expected to create the necessary incentives to drive performance throughout MDAs and their complementary private sector organizations to achieve the desired development outcomes that will boost both human system and natural resources resilience and coping range.

From the focus group discussion and some of the in-depth interviews leadership was keen among the areas respondent mentioned as an important capacity need. Respondent noted that leadership at national, local, or at organizational level have the responsibility to sign self-commitment for sustainable development and climate change response. They explained further that leadership decide, whether a city or region should go carbon neutral, promote and implement large-scale climate change adaptation policies.

Does Ghana need to increase spate of research in climate change to help respond to ongoing impact or expected impact of climate change

Much is being discovered about climate variability and changes however the impacts and possible responses to such changes have not been more accurate in any scientific research, as a result it is imperative Ghana doubles up effort in research to help anticipate possible impacts. The limitations in impacts and possible responses research results in significant areas that require more concerted effort and continues learning (AfDB et al., 2003). For example, while climate models are generally consistent regarding the warming in Africa, projected changes in precipitation are less consistent. Other examples of deficit in understanding are the links between land-use changes, climate stress and possible feedbacks; the link between climate and food insecurity in Africa, particularly the role of other multiple stresses that enhance impacts of droughts and floods; limited model of regional and local model for measure vulnerability; feature potential of adapting to climate change; the nexus between climate change and governance etc. due to these limitations in climate research effort is extremely need to increase research into diverse aspect of climate change so as to have scientific data for planning. This situation indicates that available information on climate change, though highly advance, more still need to be done in Ghana.

Does Ghana need to improve its dissemination of climate change information and Advocacy to respond to ongoing impact or expected impact of climate change?

The common impacts of climate change that is predominantly experienced in Ghana include flooding, storms and erratic rains. These variability present challenges to vulnerable groups like petty traders and small holder farmers. High penetration climate information through internet, radio, television, community centers and local forum on expected hazards will help these group planned ahead for effective adaptation. Respondents were of the view that climate information and dissemination through the right medium is necessary in Ghana. They indicated that small holder vegetable farmers need information on amount of rain in every season, market women need information on 
intensity of rain in order to protect their market wares, communities and markets located along the lake Volta need information on rains as well so they can predict possible flooding and adequately prepare, whiles other staple farmers need information on which month will the raising season began so they plan their impending planting to coincide with the season. They observed that the effective use of climate information to identify adaptation strategies and support adaptation planning in Ghana has been hindered by challenges in matching decisionmaking needs to the available information. One respondent stated that:

...the core of the challenge is that climate information is not single-sourced, but instead is produced in a wide variety of formats and at multiple scales. Decision makers in Ghana are not able to always get the information they need, when they need it, or covering the areas of interest to them.

What sort of wealth\& financial capital does Ghana need to respond to ongoing impact or expected impact of climate change?

Respondents mentioned inadequate financial resources and competition from many different needs as a critical constraint to adaptation in Ghana. it was noted that budgets for adaptation are likely to increase substantially over the years however financial resources available (official Development Assistance) continue to decrease due to Ghana recent rating of middle income status. Another effect of current financial constraints is that Ghana has not been able to properly develop project identification note (PIN) that meet international funding standard and hence are unable to access funding from various adaptation fund. A respondent indicated that adaptation to climate change will lead to additional costs for both the public and the private sector. Ghana therefore has to identify additional financial sources to boost it financial resource capacity.
What kind of material resources \& infrastructure does Ghana need to respond to ongoing impact or expected impact of climate change?

Respondents indicated that material resources needed by organizations that concentrate on the development and dissemination of relevant knowledge on climate change such as the Ghana meteorological agency, National Disaster Management Organisation, the Fire Service and other Security agencies that compliment efforts in periods of environmental perturbations are almost non existing. They therefore pointed out that it is crucial for these agency to be resourced with the needed state of the art technologies, finance, human etc. to equip them perform both anticipatory and reactive adaptive roles necessary for managing climate change stress. A respondent observed that, just like other state agencies, the Ghana Meteorological Agency which provide effective and time-bound weather information services to the Aviation, Agriculture, the aquatic industries and the general public, had operated without the use of radar since 1966 until 2012 when the government procured Surveillance Radar.

What kind of organizational\& social capital does Ghana need to respond to ongoing impact or expected impact of climate change?

Organizational and social capital is the norms and networks that enable people to act collectively (Woolcock and Narayan, 2000). Generally trust, reputation, and reciprocal action as an element of social capital have been noted to be a significant constituent in determining adaptive capacity. Social capital thus interacts with natural capital and in relation to the performance of institutions to help determines the extent to which systems cope (Woolcock and Narayan 2000) with the risks of climate change. Social capital theory indicates that individuals use their relationships to other actors in societies to 
cope with external climatic stimuli for their own and for the collective good. Respondents indicated that at the community level, social capital is the most important factor in determining autonomous and flexible adaptation.

Below presents extract of respondents views on benefits of organizational and social capital in the face of climate surprises:

....Social capital is critical to adaptation responses because it typically less costly, more comprehensive and just requires local buy-in

.......social capital is necessary in both facilitating-new technologies and disaster relief and generating-ideas for occupational diversification and post disaster relief methodologies.

Specifically respondents mentioned that Ghana need to maintain it traditional culture of trust, reciprocity, fidelity, communal work like "nnoboa", and willingness to spread information on ongoing or impending environmental perturbation.
Does Ghana need equitable empowerment and access to resources to have the right capacity to adapt to climate change?

Respondents noted that many people that are vulnerable to climate change are under pressure from forces such as high dependency ratio, resource depletion, nonawareness of climatic changes, social exclusion and inequitable empowerment. Respondents further indicated that climate adaptation goals can be advanced by changes in policies that empower women and children reduces dependency ratio, ensure equitable resource distribution, lessen pressure on resources, improve management of environmental risks, and enhance adaptive capacity. Climate adaptation and equity goals can be jointly pursued through initiatives that promote the welfare of the poorest members of society.

Challenges of improving capacity needed for climate change responds in Ghana

Respondents provided the following as some of the common challenges that Ghana faces in improving its adaptation capacity: (the responses are classified)

Policy Weak environmental policy and standards; Limited resources in policy makers development, implementation, monitoring and evaluation; Poor informal and formal rules interface and harmonization; Fragmented public institutions with overlapping roles; Poor coordination among MDAs

Students Untapped student research into community level adaptation planning Low absorptive capacity of institutions to absorb young scientist to undertake research; Low public awareness of climate change

Business Poor protection of property rights; Weak enforcement of existing policies on community innovations (this discourage foreign direct investments in projects that are climate resilient); Bureaucratic challenges for project approvals discourage potential investor; Complicated legalities; Corruption; Lack of co-ordination between different authorities

Researchers/ Poor data and information sharing; low technology transfer; Non-complementary lecturers rather than duplicative functions, lack of adaptation targets; Non existing local research fund; Limited local research; Low voice of local researchers; Limited involvement of local expertise in planning; Poor research infrastructure 


\section{Conclusion and Recommendation}

Climate change is evident and its impact is far more greater than often predicted. The most vulnerable groups are the poor in developing countries where high levels of poverty, lack of social safety nets and access to education and healthcare have intensified their vulnerability to climatic change. As a result adaption has become important development and survival issues receiving much attention in both development policy and practice. Ghana, like many other African countries, faces enormous social, economic and environmental challenges that are likely to be exacerbated by the impacts of climate change. At both the individual and the national levels, climate change is of serious concern because of the nation's overdependence on climate-sensitive sectors, such as hydro-power generation, agriculture, fisheries and wildlife resources.

Presently, some of the challenges facing Ghana are the inadequate climate science professionals and low institutional capacities. Adaptation is a survival threat and hence a priority and not developmental option. Therefore Ghana's efforts to become middle income economy can be short lived if local capacity to respond to climate stress is not developed. There is the need to increase Ghana' research capacity to be able to better forecast, develop early warning systems. Public sector institutions should be well resource with the right and sufficient material need. Center of excellence should be set up that concentrate on climate change research. These centers should be made financially and politically autonomous. Timely communication is also very necessary to ensure that research outputs are put to effective use. The lopsidedness of communication between supply-side and demand-side of climate information is very clear in Ghana. Farmers are unable to know changing raining patterns and to plant accordingly.
Government needs to provide enough resource for funding both research projects and hard-engineering activities that will help communities adapt to flooding, drought, storms etc. Such fund will provide resources that could be used to build institutional capacity. To develop viable Project Identification Note (PIN) to attract bilateral and multilateral support, institutional capacity needs to be improved which cannot be done without necessary funds. Traditional norms and values that help prevent environmental destruction should be well upheld and integrated into any adaptation action. Social exclusion also worsens vulnerability and hence women and children should be empowered through equitable access to economic resource. Finally attraction of modern technologies and utilization of indigenous technologies are very necessary in adaptation. Whiles the formal needs quick penetration the later requires innovations and adoption.

\section{References}

Adger, N.W. and Neil, W. (2003). Social capital, collective action, and adaptation to climate change. Economic Geography, 79(4): 87--404.

Adger, W.N. (2006). Vulnerability. Global Environmental Change, 16(3): 268281.

Adger, W.N., Eakin, H. and Winkels, A. (2007). Nested and networked vulnerabilities in South East Asia. Global Environmental Change and the South-eastAsian Region: An Assessment of the State of the Science, L. Lebel, et al., Eds., Island Press, Washington, District of Columbia, in press.

AfDB (2010). The Cost of Adaptating to Climate Change in Africa. Accesses, 20/04/2014

at http://www.afdb.org/fileadmin/uploads/ afdb/Documents/Project-and- 
Operations/Cost $\% 20$ of\%20Adaptation

$\% 20$ in\%20Africa.pdf

AfDB, ADB, DFID, DGIS, EC, BMZ, OECD, UNDP, UNEP and WB, 2003: Poverty and Climate change Reducing the Vulnerability of the Poor throughcAdaptation. UNEP, Nairobi, $43 \mathrm{pp}$.

Boon, E, Ahenkan, A. (2011). Assessing Climate Change Impacts on Ecosystem Services and Livelihoods in Ghana: Case Study of Communities around Sui Forest Reserve. J EcosystEcogr S3:001. doi:10.4172/2157-7625.S3-001

Butzer, K.W. (2011). Geoarchaeology, climate and sustainability: a Mediterranean perspective. Geoarchaeology, Climate Change and Sustainability, eds

Butzer, K.W., and Endfield, G.H. (2012). Critical perspectives on historical collapse. Proc Natl Acad Sci USA 109: 3628-3631.

Ghana's Second National Communication to the UNFCCC (2011)

Intergovernmental Panel on Climate Change (IPCC) (2007). Climate change 2007: impacts, adaptation and vulnerability. Contribution of working group II to the fourth assessment report of the IPCC, Cambridge University Press, Cambridge, UK,

IPCC (2001). Climate Change 2001: Impacts, Adaptation, and Vulnerability, Summary for Policymakers and Technical Summary of the Working Group II Report. Geneva: IPCC.

Jones, L. (2010). Overcoming Social Barriers to Adaptation.ODI Background Note. London: ODI (www.odi.org.uk/resources/download/4 945.pdf)

Kuriakose, A., Livia, B. and Bachofen, C. (2009). Assessing vulnerability and adaptive capacity to climate risks: Methods for investigation at local and national levels. Washington, DC: World Bank.

Lemos, M.C., Agrawal, A., Eakin, H., Nelson, D.R., Engle, N., Johns, O. (2013). Building adaptive capacity in less developed countries. In: Asrar, G.R., Hurrell, J.W. (Eds.), Climate Science for Serving Society: Research, Modeling and Prediction Priorities. Springer.

Lemos, M.C., Boyd, E., Tompkins, E., Osbahr, H., Liverman, D. (2007). Developing adaptation and adapting development. $\quad$ Ecol. $\quad$ Soc.12 ,http://www.ecologyandsociety. org/issues/article.php/2133

McMichael, A.J. and Lindgren, E. (2011). Climate change: Present and future risks to health, and necessary responses. J. Intern. Med., 270:401-413.

National Research Council (2010).Advancing the Science of Climate Change. Prepublication. Washington, D.C.: National Academies Press. Available online

at
http://www.nap.edu/catalog.php?record $i d=12782$.Accesed; 15/03/13

Organisation for Economic Co-Operation and Development (OECD) (2008). Climate Change Mitigation: what do we do? OECD

Smit, B. and Wandel, J. (2006). Adaptation, adaptive capacity and vulnerability. Global Environmental Change 16: 286292

Smithers, R.J., Cowan, C. Harley, M. Hopkins, J.J. Pontier, H. and Watts, O. (2008). England Biodiversity Strategy Climate Change Adaptation Principles. Department for Environment, Food and Rural Affairs.

Tanner, T. and Mitchell, T. (2007). 'Pro-poor climate change adaptation: A research agenda'. IDS In Focus on Climate Change. 
Rising to the Challenge: What sort of Capacity does Ghana need.................MUSAH-SURUGU \& AHENKAN

UKCIP (2003). Building Knowledge for a Changing Climate. The impacts of climatechange on the built environment. UK Climate Impacts Programme and Engineering and Physical Sciences Research Council, Oxford.

UNDP Climate Change pages.http://www.undp.org/climatechan ge/

Wilbanks, T. J. and Kates R. W. (2010). Beyond Adapting to Climate Change: Embedding Adaptation in Responses to Multiple Threats and Stresses." Annals of the Association of American Geographers, 100(4): 719 - 728.

Woolcock, M. (1998). Social capital and economic development: Toward a theoretical synthesis and policy framework. Theory and Society 27 (2):151-208.

Woolcock, M., and Narayan, D. (2000). Social capital: Implications for development theory, research and policy. World Bank Research Observer, 15: 225-249.

World Bank (2008). The Pilot Program for Climate Resilience under the Strategic Climate Fund. Washington, DC: World Bank. Available at: $<$ http://siteresources.worldbank.org/IN TCC/Resources/PCRGovernanceStruct ure.pdf>.acessed, 10/02/2014

Yohe, G. and, Tol, R. (2002). Indicators for social and economic coping capacitymoving toward a working definition of adaptive capacity. Global Environmental Change, 12: 25-40. 